\title{
Acquisition of negative complement regulators by the saprophyte Leptospira biflexa expressing LigA or LigB confers enhanced survival in human serum
}

\author{
Mónica M. Castiblanco-Valencia ${ }^{a}$, Tatiana R. Fraga ${ }^{a}$, Leandro C.D. Breda ${ }^{\text {a }}$, \\ Sílvio A. Vasconcellos ${ }^{\mathrm{b}}$, Cláudio P. Figueira ${ }^{\mathrm{c}}$, Mathieu Picardeau ${ }^{\mathrm{d}}$, Elsio Wunder ${ }^{\mathrm{e}}$, \\ Albert I. Ko ${ }^{\mathrm{c}, e}$, Angela S. Barbosa ${ }^{\mathrm{f}}$, Lourdes Isaac ${ }^{\mathrm{a}, *}$ \\ a Department of Immunology, Institute of Biomedical Sciences, University of São Paulo, São Paulo, Brazil \\ ${ }^{\mathrm{b}}$ Faculty of Veterinary Medicine, University of São Paulo, São Paulo, Brazil \\ c Oswaldo Cruz Foundation, Salvador, Bahia, Brazil \\ ${ }^{\mathrm{d}}$ Institut Pasteur, Biology of Spirochetes Unit, Paris, France \\ e Department of Epidemiology of Microbial Diseases, Yale University, EUA, CT, USA \\ ${ }^{\mathrm{f}}$ Laboratory of Bacteriology, Butantan Institute, São Paulo, Brazil
}

\section{A R T I C L E I N F O}

\section{Article history:}

Received 22 January 2016

Received in revised form 8 March 2016

Accepted 9 March 2016

Available online 11 March 2016

\section{Keywords:}

Leptospira

Complement

Immune evasion

Lig proteins

Factor $\mathrm{H}$

C4BP

\begin{abstract}
A B S T R A C T
Leptospiral immunoglobulin-like (Lig) proteins are surface exposed molecules present in pathogenic but not in saprophytic Leptospira species. We have previously shown that Lig proteins interact with the soluble complement regulators Factor H (FH), FH like-1 (FHL-1), FH related-1 (FHR-1) and C4b Binding Protein (C4BP). In this study, we used the saprophyte L. biflexa serovar Patoc as a surrogate host to address the specific role of LigA and LigB proteins in leptospiral complement evasion. L. biflexa expressing LigA or LigB was able to acquire FH and C4BP. Bound complement regulators retained their cofactor activities of $\mathrm{FI}$ in the proteolytic cleavage of $\mathrm{C} 3 \mathrm{~b}$ and $\mathrm{C} 4 \mathrm{~b}$. Moreover, heterologous expression of $\operatorname{lig} A$ and $\operatorname{lig} B$ genes in the saprophyte L. biflexa enhanced bacterial survival in human serum. Complement deposition on ligtransformed $L$. biflexa was assessed by flow cytometry analysis. With regard to MAC deposition, $L$. biflexa expressing LigA or LigB presented an intermediate profile: MAC deposition levels were greater than those found in the pathogenic L. interrogans, but lower than those observed for L. biflexa wildtype. In conclusion, Lig proteins contribute to in vitro control of complement activation on the leptospiral surface, promoting an increased bacterial survival in human serum.

(c) 2016 European Federation of Immunological Societies. Published by Elsevier B.V. All rights reserved.
\end{abstract}

\section{Introduction}

Leptospirosis is an important human and veterinary health problem and one of the most widespread zoonosis in the world. The Caribbean, Central and South America, as well as Southeast Asia and Oceania, are highly endemic for the disease [1]. In urban environments, rodent-borne transmission is the predominant epidemiological pattern of the disease. Flood-prone regions lacking proper sanitation facilities deeply contribute to epidemics of leptospirosis in tropical areas [2].

The genus Leptospira includes pathogenic and saprophytic species, which are classified into more than 300 serovars based on

\footnotetext{
* Corresponding author at: Av. Prof. Lineu Prestes 1730, 05508-900 São Paulo, SP, Brazil.

E-mail address: louisaac@icb.usp.br (L. Isaac).
}

the structural heterogeneity of the lipopolysaccharide (LPS) carbohydrate moiety [3]. Pathogenic Leptospira have evolved different immune evasion strategies that allow them to survive and spread in the host (reviewed in [4]). In this context, it has been demonstrated that pathogenic Leptospira strains are more resistant to the action of the human complement system than the saprophytic ones, such as Leptospira biflexa. Serum resistance is achieved by the acquisition of negative complement regulators on their surfaces, such as Factor $\mathrm{H}(\mathrm{FH})$ and $\mathrm{C} 4 \mathrm{~b}$ Binding Protein (C4BP), and also by the secretion of proteases that inactivate key complement proteins from the three pathways [5-7].

$\mathrm{FH}$, a 150-kDa plasma protein, is the major negative regulator of the alternative pathway (AP) of complement. It inhibits AP by accelerating the decay of the $\mathrm{C} 3$ convertase, $\mathrm{C} 3 \mathrm{bBb}$, and by acting as a cofactor of Factor I (FI) in C3b cleavage [8-10]. Leptospira-bound $\mathrm{FH}$ remains functionally active and confers a protective role, being 
crucial for bacterial survival in human [6,11]. Pathogenic Leptospira also have the ability to bind human C4BP, a 570-kDa plasma glycoprotein that is a key fluid phase inhibitor of the classical and lectin pathways of complement $[12,13]$. C4BP interferes with the assembly and decay of the C3-convertase, $\mathrm{C} 4 \mathrm{bC2a}$, and acts as a cofactor of FI in the proteolytic inactivation of C4b. Leptospira-bound C4BP retains cofactor activity, indicating that the acquisition of this complement regulator may contribute to leptospiral serum resistance [5].

In a recent work we demonstrated that Leptospiral Immunoglobulin-like proteins $\mathrm{A}$ and $\mathrm{B}$ (LigA and LigB) interact with $\mathrm{FH}, \mathrm{C} 4 \mathrm{BP}$ and also with two other members of the $\mathrm{FH}$ family: FH like-1 (FHL-1) and FH related-1 (FHR-1). Both FH and C4BP bound to the Lig proteins remain functional, acting as cofactors for $\mathrm{FI}$ in the proteolytic cleavage of $\mathrm{C} 3 \mathrm{~b}$ and $\mathrm{C} 4 \mathrm{~b}$, respectively [11]. The lig genes are present in pathogenic but not in saprophytic Leptospira species, and their expression is associated with host infection, being controlled by osmolarity, a key environmental factor which enhances binding of Leptospira to host cells [14,15]. In vitro studies have shown that Lig proteins interact with extracellular matrix proteins such as fibronectin, laminin, collagen, fibrinogen, elastin and tropoelastin [16-23]. Antibody responses to Lig proteins are induced in human leptospirosis patients and in infected animals [24-26]. A fragment of the LigA protein has been shown to be a promising vaccine candidate, conferring high-levels of protection in hamster models of leptospirosis [27,28]. Together these findings indicate that Lig proteins are multifunctional proteins that may contribute to Leptospira adhesion and immune evasion during infection. However, disruption of the $\operatorname{lig} B$ gene did not affect Leptospira virulence in hamster model [29]. Expression of other leptospiral surface proteins involved in host colonization may compensate the loss of LigB expression, a phenomenon known as functional redundancy [29].

In this study, we used the saprophyte L. biflexa serovar Patoc as a surrogate host to address the specific role of Lig proteins in leptospiral immune evasion. In a previous work, Figueira and colleagues [30] reported that heterologous expression of LigA and LigB in $L$. biflexa was able to confer enhanced bacterial adhesion to eukaryotic cells and fibronectin in vitro [30], which prompted us to use this system to analyze the isolated role of Ligs in the leptospiral complement evasion.

\section{Material and methods}

\subsection{Complement proteins, antibodies and sera}

The complement proteins purified from human plasma ( $\mathrm{FH}$, C4BP, C3b and C4b) and the goat anti-human C3 and anti-human C4 polyclonal antibodies were purchased from Complement Technology. Goat anti-human FH polyclonal antibody was obtained from Quidel. Rabbit anti-human C4BP and anti-human C5b-9 (MAC) polyclonal antibodies were purchased from Calbiochem. Donkey anti-goat IgG FITC conjugated and donkey anti-rabbit IgG FITC or PE conjugated were obtained from Abcam. Normal human serum (NHS) was obtained from healthy volunteers, after informed consent (869/CEP). Inactivated NHS (HI-NHS) was prepared by heating the serum at $56^{\circ} \mathrm{C}$ for $60 \mathrm{~min}$.

\subsection{Bacteria strains}

The following strains were used in this study: non-pathogenic $L$. biflexa serovar Patoc strain Patoc I (Patoc wt), pathogenic L. interrogans serovar Kennewicki strain Fromm and L. biflexa serovar Patoc strain Patoc I expressing LigA (Patoc ligA) or LigB (Patoc ligB) [30]. Leptospira strains were cultivated at $29^{\circ} \mathrm{C}$ for seven days, under aerobic conditions in liquid EMJH medium (Difco) supplemented with Leptospira EMJH Enrichment (BD). Patoc ligA and Patoc ligB were grown in culture medium containing spectinomycin at the final concentration of $50 \mu \mathrm{g} / \mathrm{ml}$ [30].

\subsection{Interaction of Leptospira strains with $\mathrm{FH}$ and C4BP}

Freshly harvested leptospires $\left(1 \times 10^{8}\right.$ bacteria) were washed with PBS pH 7.4 and incubated with $10 \%$ NHS, as a source of $\mathrm{FH}$ and $\mathrm{C} 4 \mathrm{BP}$, for $60 \mathrm{~min}$ at $37^{\circ} \mathrm{C}$. Leptospires were then washed five times with PBS, harvested and subjected to $12 \%$ SDS-PAGE under reducing conditions. The proteins were transferred to nitrocellulose membranes, and nonspecific binding sites were blocked using $10 \%(\mathrm{w} / \mathrm{v})$ dried milk in PBS-Tween $(0.05 \%)(\mathrm{pH} 7.4)$ overnight at $4{ }^{\circ} \mathrm{C}$. The membranes were incubated with goat anti-human $\mathrm{FH}$ (1:10000) or rabbit anti-human C4BP (1:5000) polyclonal antibodies, followed by peroxidase-conjugated secondary antibodies, for 60 min. Positive signals were detected by enhanced chemiluminescence (SuperSignal West Pico, Pierce). Densitometry analysis of the bands was performed using the program ImageJ.

\subsection{Serum susceptibility assay}

Freshly harvested leptospires were washed once with PBS pH 7.4 and counted by dark-field microscopy using a Petroff-Hausser chamber. Bacteria $\left(5 \times 10^{8}\right)$ were incubated with 20,40 and $60 \%$ NHS, or $60 \% \mathrm{HI}-\mathrm{NHS}$ for 60 or $120 \mathrm{~min}$ at $37^{\circ} \mathrm{C}$. After incubation, leptospiral survival in each treatment was assessed by counting viable bacteria. Leptospires susceptible to complement attack fragment in fine particles, losing their typical morphology. Three independent experiments were performed. The treatment with HI-NHS was considered as $100 \%$ of survival.

\subsection{Cofactor activity assay}

Cofactor activity of FH or C4BP bound to leptospires was assessed by measuring FI-mediated cleavage of $\mathrm{C} 3 \mathrm{~b}$ (FH as a cofactor) or $\mathrm{C} 4 \mathrm{~b}$ ( $\mathrm{C} 4 \mathrm{BP}$ as a cofactor). Leptospires $\left(2 \times 10^{8}\right.$ bacteria) were incubated with $5 \%$ NHS or $2 \mu \mathrm{g}$ of $\mathrm{FH}$ or C4BP for $60 \mathrm{~min}$ at $37^{\circ} \mathrm{C}$. After washing with PBS, $250 \mathrm{ng}$ of FI and $500 \mathrm{ng}$ of C3b or C4b were added. The reactions were incubated for 60,120 and $240 \mathrm{~min}$ at $37^{\circ} \mathrm{C}$, and then subjected to Western blotting. The cleavage fragments of $\mathrm{C} 3 \mathrm{~b}$ and $\mathrm{C} 4 \mathrm{~b}$ were detected with goat anti-human $\mathrm{C} 3$ or anti-human C4 polyclonal antibodies (1:5000), followed by incubation with secondary peroxidase-conjugated antibodies $(1: 10000)$, by enhanced chemiluminescence (SuperSignal West Pico, Pierce).

\subsection{Analysis of complement deposition by flow cytometry}

Leptospires ( $2 \times 10^{8}$ bacteria) were incubated with $20 \%$ NHS or PBS (negative control) in a final volume of $100 \mu \mathrm{l}$ for $60 \mathrm{~min}$. After five washes with PBS, bacteria were incubated with anti-human C3, anti-human C4 or anti-human MAC polyclonal antibodies (1:100; in PBS containing 1\% BSA) for 30 min. Leptospires were then washed with PBS, and mouse anti-goat IgG FITC-conjugated or anti-rabbit IgG PE-conjugated (1:200; in PBS containing $1 \%$ BSA) were added and incubated for $30 \mathrm{~min}$. After three washes, bacteria were suspended with PBS in a final volume of $300 \mu$ l. As negative controls, untreated leptospiral suspensions were incubated only with primary and secondary antibodies. Leptospires were detected using log-forward and log-side scatter dot-plot. The gate was drawn to exclude debris and larger aggregates of bacteria-10,000 bacteria/events were captured per experiment. Data are expressed as Mean Fluorescence Intensity (MFI) \pm SE of three independent experiments each performed in triplicate on a Fluorescent Acti- 
A.

anti-FH

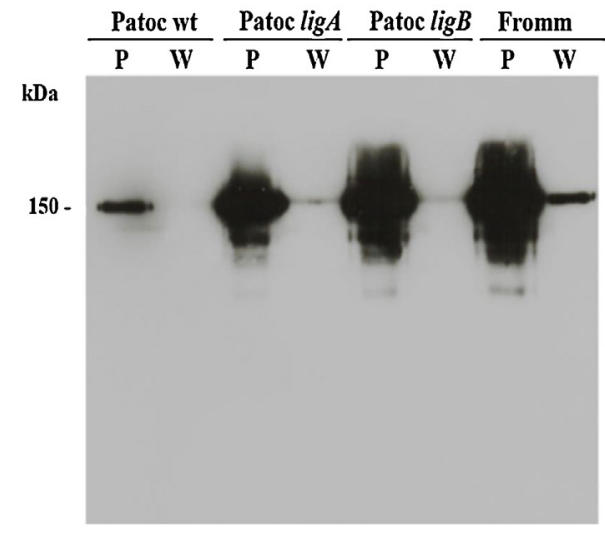

C.

FH binding

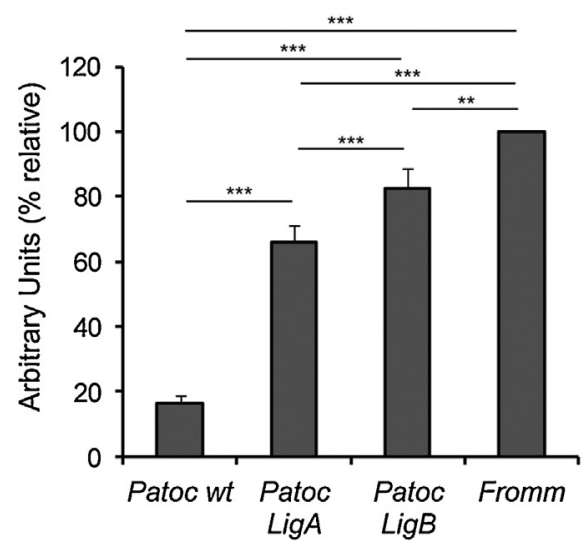

B.

anti-C4BP

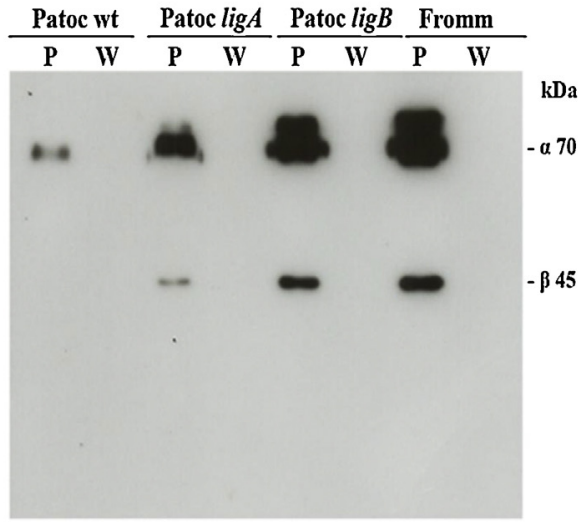

D.

\section{C4BP binding}

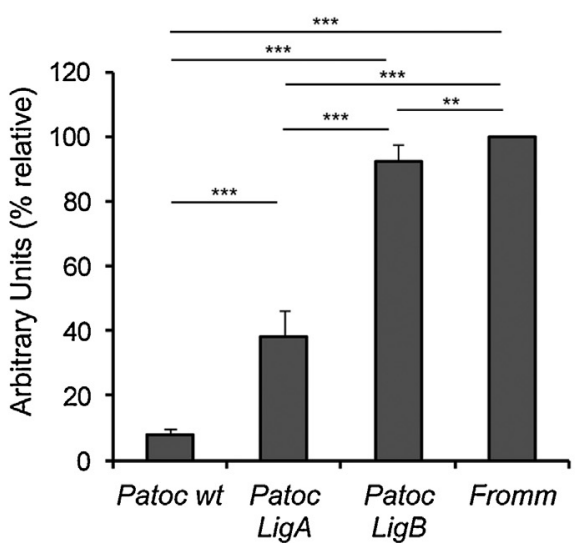

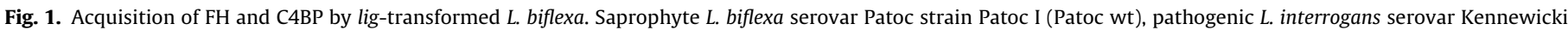

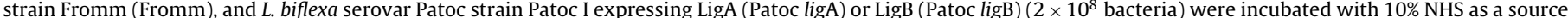

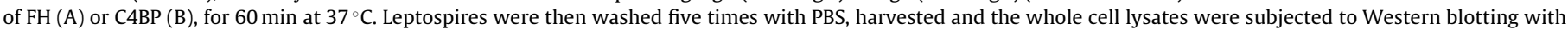

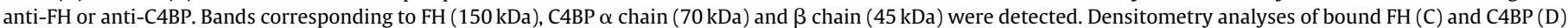

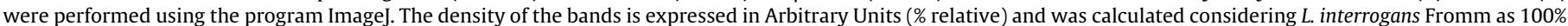
of binding. (P) bacterial pellets; $(\mathrm{W})$ aliquots of the last wash.

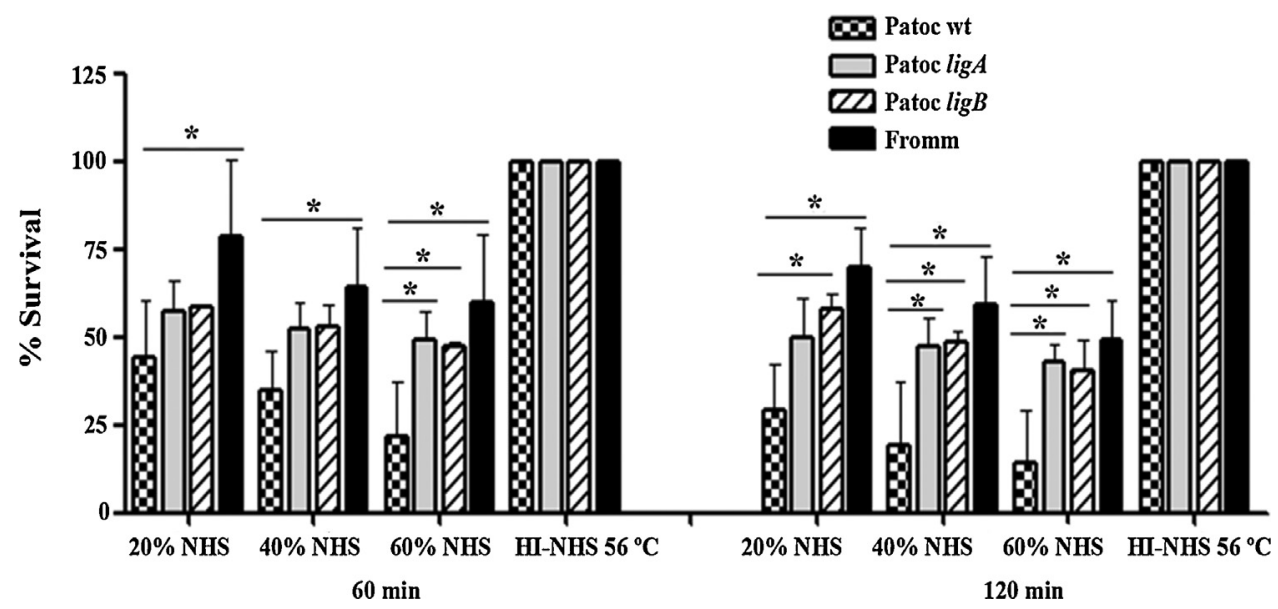

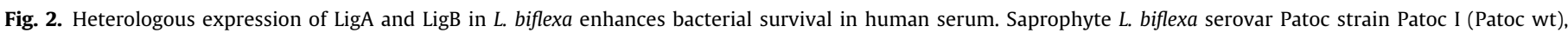

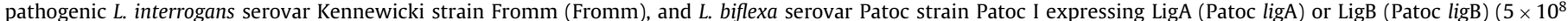

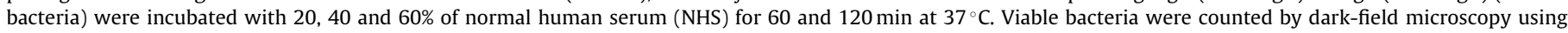

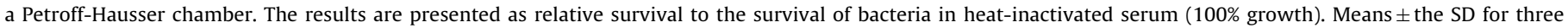
independent experiments, each performed in duplicate are shown. The data were analyzed with one way ANOVA test.* $(p<0.05)$. 

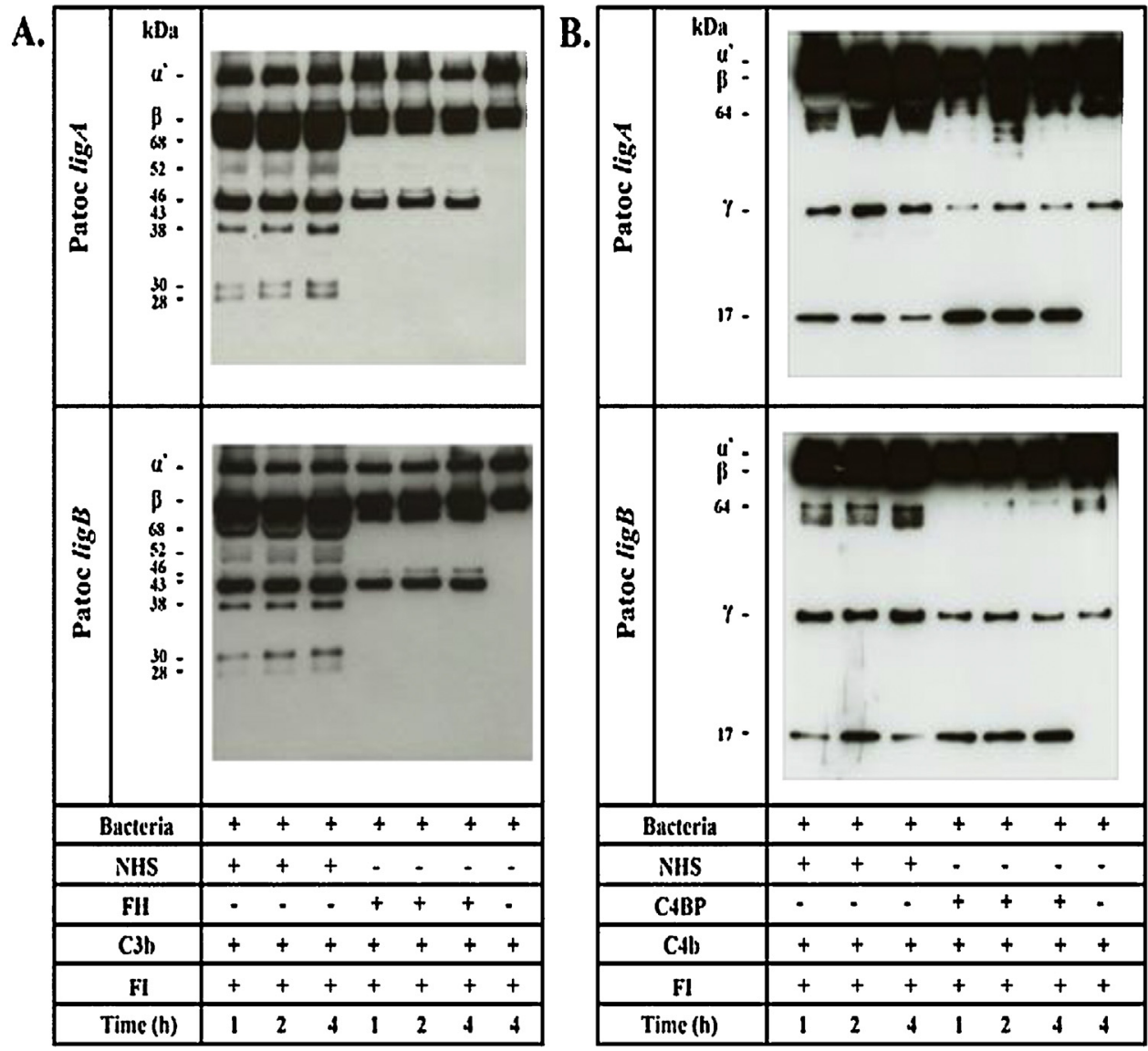

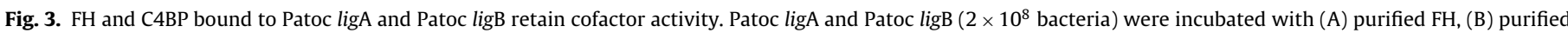

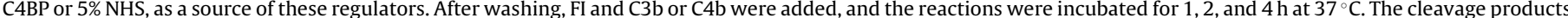

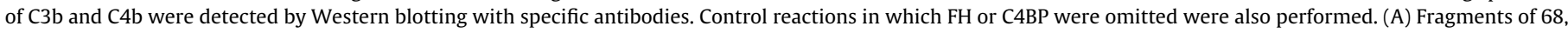

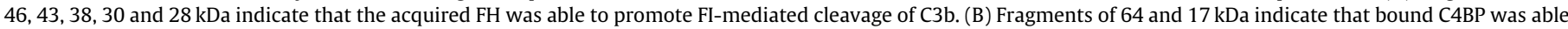
to promote FI-mediated cleavage of $\mathrm{C} 4 \mathrm{~b}$.

vated Cell Sorter (FACS) Canto II (Benton Dickson). Data were analyzed by FlowJo Software (version 8.7).

\subsection{Statistical analysis}

Data were analyzed using ANOVA-Tukey's Multiple Comparison Test and $p$ values are indicated in each figure legend.

\section{Results}

\subsection{Patoc ligA and Patoc ligB interact with $\mathrm{FH}$ and $C 4 B P$}

LigA and LigB expression by the lig-transformed Patoc strains was previously assessed by Western blot analysis [30]. Both strains showed levels of protein comparable to the production by a low in vitro-passaged $L$. interrogans virulent strain. In addition, Patoc wt, $\operatorname{lig} A$, and $\operatorname{lig} B$ strains were shown to have similar cell growth kinetics in EMJH liquid medium and immunofluorescence studies indicated that LigA and LigB are surface-exposed when expressed in transformed Patoc strains [30].

In a previous work we have shown that Lig proteins interact with the soluble complement regulators FH and C4BP [11]. To assess if lig-transformed $L$. biflexa strains are able to acquire these negative complement regulators, bacteria were incubated with 20\% NHS, and then submitted to Western blot analysis with specific antibodies against the complement proteins. Both Patoc ligA and Patoc ligB acquired FH and C4BP from human serum (Fig. 1). The wild type $L$. biflexa bound negligible amounts of both complement regulators to its surface, but acquisition of FH and C4BP was markedly increased by the expression of Lig proteins in L. biflexa, suggesting a role for these molecules in Leptospira complement evasion.

\subsection{Heterologous expression of ligA and ligB genes in the saprophyte L. biflexa enhances bacterial survival in human serum}

To specifically address the role of LigA and LigB in complement evasion, lig-transformed $L$. biflexa strains were subjected to serum susceptibility assays. Leptospires were incubated in different NHS concentrations, and viable bacteria were then counted using dark field microscopy. The survival percentage of Patoc ligA and Patoc ligB was approximately 2 -fold higher in $60 \%$ NHS than that of Patoc wt (Fig. 2, left). Differences in survival were even more pronounced when bacteria were incubated in NHS for 120 min (Fig. 2, right). In $60 \%$ NHS ( $120 \mathrm{~min}$ ), about $85 \%$ of Patoc wt were eliminated by complement-mediated lysis, while approximately $50 \%$ of Patoc ligA and Patoc lig $B$ remained viable. The survival rates of lig-transformed $L$. biflexa strains were intermediate between the ones observed for the saprophyte $L$. biflexa and the pathogenic L. interrogans (Fig. 2). This profile indicates that heterologous expression of $\operatorname{lig} A$ and $\operatorname{lig} B$ in L. biflexa enhances in vitro survival of this saprophytic strain in the presence of complement system. However, other molecules expressed by the pathogenic $L$. interrogans strain may also contribute to complement evasion. 

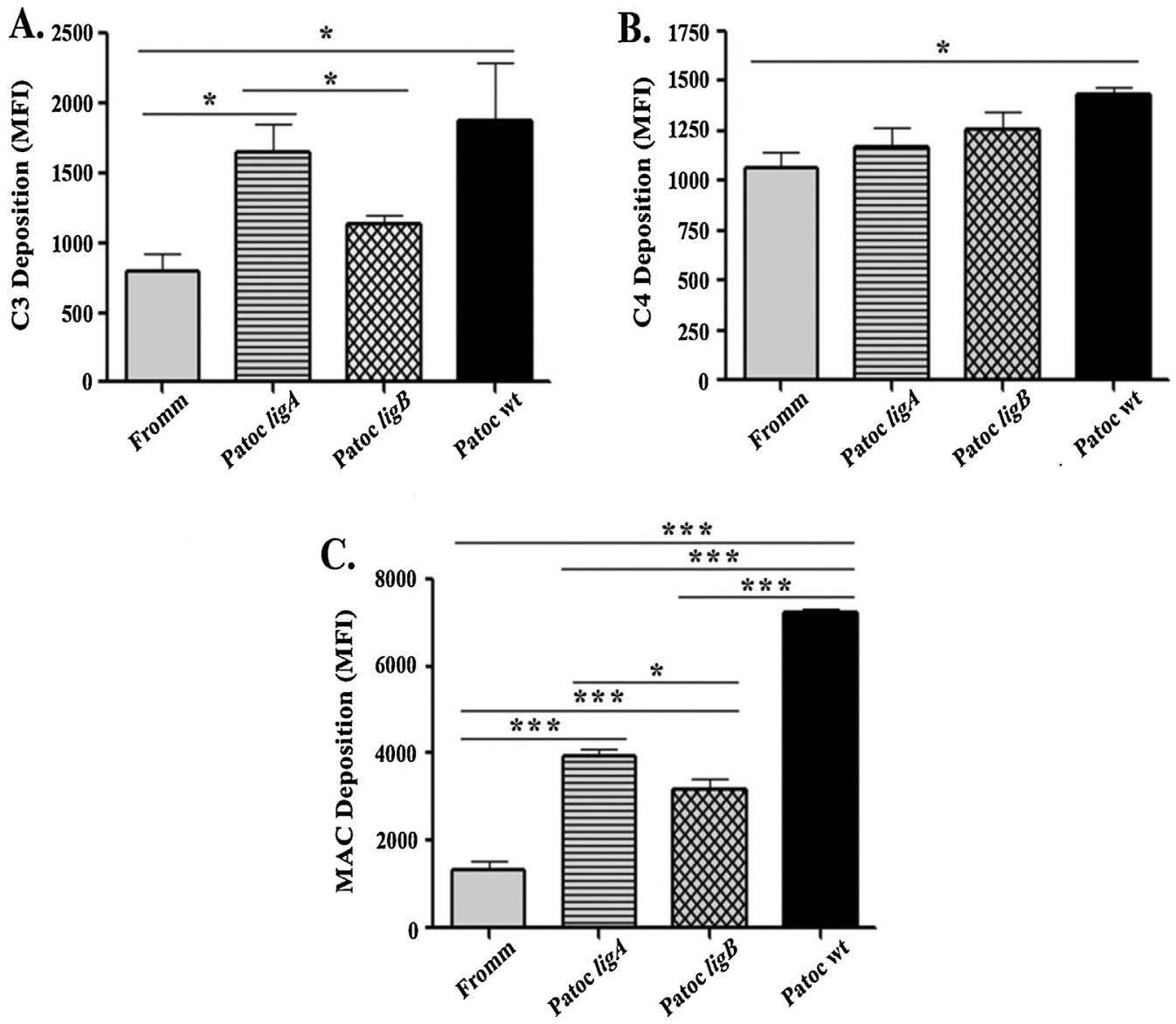

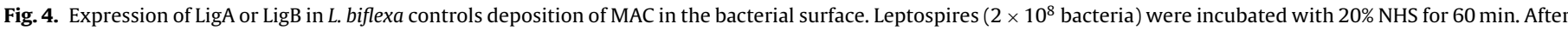

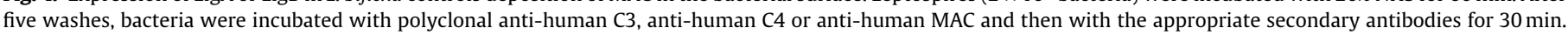

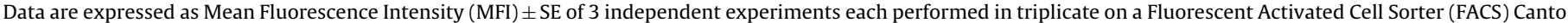
II (Benton Dickson). Data were analyzed using ANOVA-Tukey's Multiple Comparison Test * $p<0.005)$.

\subsection{FH and C4BP bound to Patoc ligA and Patoc ligB retain cofactor activity}

As lig-transformed L. biflexa strains acquire negative complement regulators and present an increased survival in human serum compared to L. biflexa wt, we decided to assess the functionality of these complement molecules bound to the bacterial surface. Leptospires were incubated with purified $\mathrm{FH}, \mathrm{C4BP}$ or NHS and, after washing, the serine protease FI and the substrates $\mathrm{C} 3 \mathrm{~b}$ ( $\mathrm{FH}$ as a cofactor) or C4b (C4BP as a cofactor) were added. The cleavage fragments of $\mathrm{C} 3 \mathrm{~b}$ and $\mathrm{C} 4 \mathrm{~b}$ were detected by Western blotting with specific antibodies. FH and C4BP bound to Patoc ligA and to Patoc $\operatorname{lig} B$ were capable of acting as cofactors of $F I$ in the cleavage of $C 3 b$ (Fig. 3A) and C4b (Fig. 3B). The degradation of the C3b $\alpha^{\prime}$-chain $(\sim 101 \mathrm{kDa})$ generated fragments of approximately $68,46,43,38$, 30 and $28 \mathrm{kDa}$ when NHS was used as a source of FH (Fig. 3A). The cleavage of the C4b generated bands of approximately $64 \mathrm{kDa}$ and $17 \mathrm{kDa}$ (Fig. 3B). C3b and C4b cleavages can be already detected in the first hour of incubation. Interestingly, cofactor activities were more efficient when serum was used as a source of FH or C4BP. Taken together, our data strongly suggest that Lig proteins may play an important role in leptospiral resistance to complementmediated killing.

\subsection{Patoc ligA and Patoc ligB control MAC deposition}

The enhanced survival of lig-transformed L. biflexa strains in human serum prompted us to further investigate the deposition of other complement proteins on the bacterial surface. Leptospires were incubated with human serum and then specific antibodies against $\mathrm{C} 3, \mathrm{C} 4$ or MAC were added. Complement deposition was analyzed by flow cytometry. A reduced deposition of C3/C3 fragments was observed on Patoc lig $B$ compared to Patoc wt, and no significant difference was found between Patoc ligB and $L$. interrogans regarding C3 deposition. However, Patoc ligA significantly presented greater levels of $\mathrm{C} 3$ deposition compared to $L$. interrogans (Fig. 4A). The profile of C4/C4 fragments deposition was more homogeneous among the four strains tested. In this case, a significant statistical difference was only observed between $L$. biflexa Patoc wt and L. interrogans Fromm, the latter showing lower levels of C4 deposition (Fig. 4B). With regard to MAC deposition, ligtransformed $L$. biflexa strains presented an intermediate profile: MAC deposition levels were greater than those found in $L$. interrogans (Fromm), but clearly lower than those observed for $L$. biflexa (Patoc wt) (Fig. 4C). This intermediate behavior demonstrates that the expression of Lig proteins contribute to the control of complement activation on the leptospiral surface, thus promoting an increased bacterial survival in human serum.

\section{Discussion}

Differences regarding susceptibility to host's serum among Leptospira strains were first reported in the mid-1960s [31,32]. A direct correlation between virulence and the capacity to resist complement-mediated killing was already clear at that time. Knowledge of the mechanisms beyond Leptospira resistance was 


\section{Alternative Complement Pathway}

Saprophytic L. biflexa: activation

L. biflexa LigA and L. biflexa LigB: inactivation
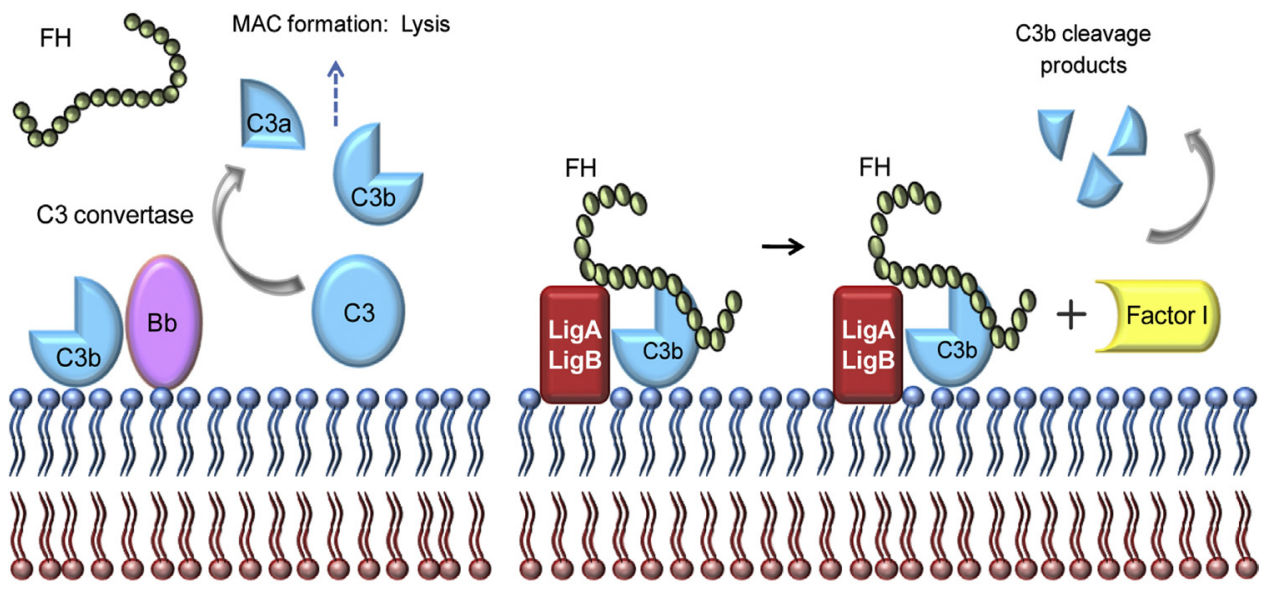

Classical and Lectin Complement Pathways

Saprophytic L. biflexa: activation

L. biflexa LigA and L. biflexa LigB: inactivation
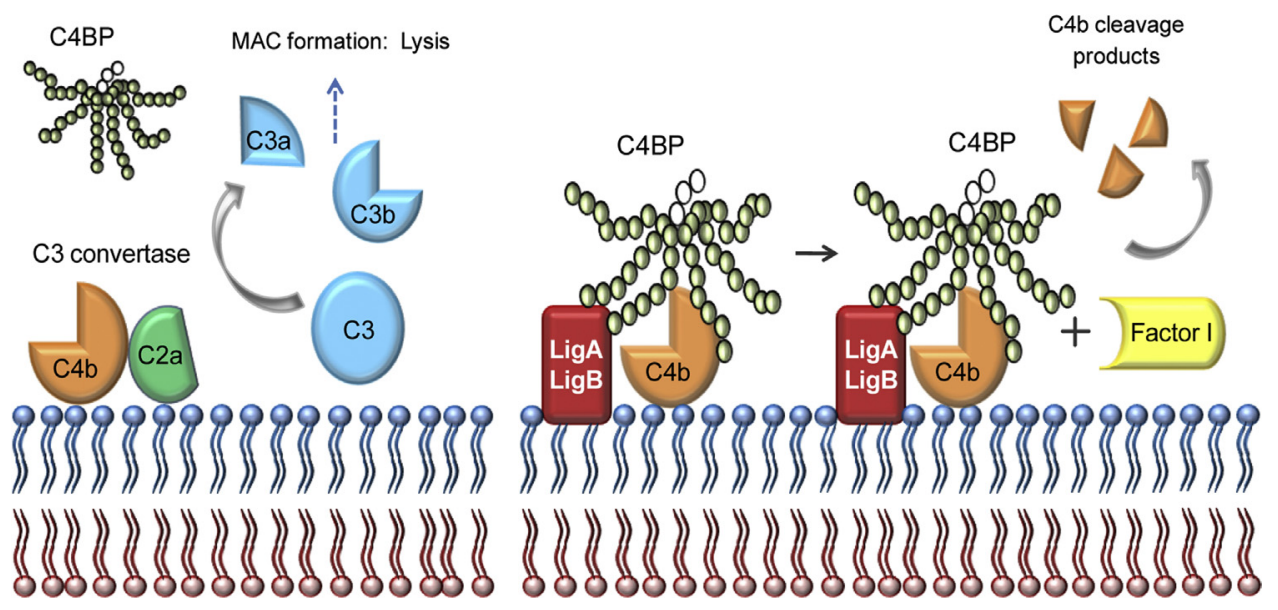

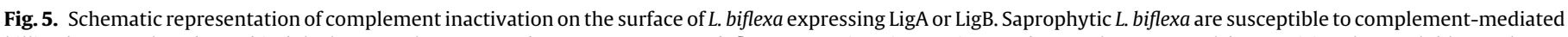

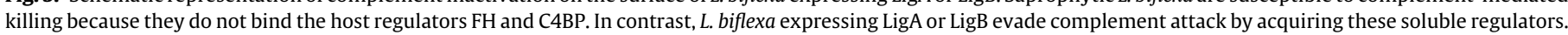

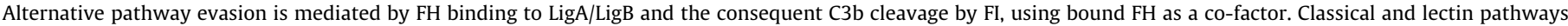

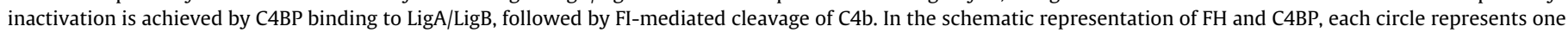
SCR domain. Open circles indicate the three SCR domains of the C4BP $\beta$-chain.

expanded over the last years by the demonstration that pathogenic Leptospira strains present multiple complement evasion strategies such as the secretion of proteases that inactivate key complement proteins [7] and the acquisition of soluble host complement regulators on their surfaces [5,6,11,33,34]. By binding these fluid-phase regulators virulent strains avoid serum bactericidal activity more efficiently than culture-attenuated or non-pathogenic Leptospira strains $[5,6]$.

In a recent report, we have shown that recombinant LigA and LigB bind FH, FHL-1, FHR-1 and C4BP [11], thus potentially enabling control of host's innate immune responses. To further evaluate the relevance of these multifunctional surface proteins in leptospiral complement evasion, we employed the non-pathogenic $L$. biflexa serovar Patoc as a surrogate host expressing LigA or LigB. It has been previously shown that $L$. biflexa serovar Patoc is susceptible to serum bactericidal activity [5,6] and is devoid of all genes that encode well-characterized leptospiral immune evasion proteins described to date, including LenA, LenB, LigA, LigB, and LcpA [11,34-36]. In this work, the capacity of lig-transformed L. biflexa strains to acquire FH and C4BP from human serum was evaluated. Our data demonstrate that Patoc ligA and Patoc ligB bind significant amounts of both complement regulators (Fig. 1), what can explain an increased survival of both strains in human serum compared to Patoc wt (Fig. 2). From our results, we can infer that Lig proteins are important players in conferring leptospiral serum resistance in vitro. In addition, other surface proteins, such as LenA, LenB and LcpA [34-36], may also contribute to this process, ensuring a successful survival of these spirochetes inside the host.

Functionality of $\mathrm{FH}$ and C4BP bound to Patoc ligA and Patoc ligB was also assessed. Both complement regulators retained cofactor activity when purified proteins or human serum were used as a complement source (Fig. 3). Cleavages of C3b and C4b were more 
efficient in the presence of human serum, probably due to a more preserved structural conformation of both complement regulators, which did not undergo a purification process. In Patoc lig $A$ and Patoc $\operatorname{lig} B$, the degradation profile of C3b using NHS as a source of FH was similar to that observed for the virulent strain $L$. interrogans serovar Pomona [11]. In both cases, FI cleaved C3b $\alpha$ ' chain $(110 \mathrm{kDa})$ generating cleavage products ranging from 28 to $68 \mathrm{kDa}$.

Next, we evaluated deposition of complement components $\mathrm{C} 3$ and C4 fragments and MAC on the surface of lig-transformed $L$. biflexa strains. According to our data, Patoc ligB displayed a reduced deposition of C3 compared to Patoc wt. However, there was no significant difference between Patoc ligA and Patoc wt (Fig. 4A). It is worth to mention that $\mathrm{C} 3$ deposition on serum resistant and serum sensitive Leptospira strains has been previously assessed $[5,6]$. Immunofluorescence microscopy assays revealed a similar pattern of C3 deposition on the surface of both pathogenic and non-pathogenic strains. Nevertheless, the late complement components C5, C6, C8 and MAC were detected only on the surface of the sensitive strain Patoc [6].

In the present work, no striking differences were observed regarding C4 fragments deposition (Fig. 4D), thus confirming previous data by our group demonstrating that Leptospira serumsensitive, -intermediate, and -resistant strains bind similar amounts of C4 [5]. As expected, the levels of MAC deposition on the serum-sensitive strain Patoc wt and the serum-resistant strain Fromm differed substantially (Fig. 4D). MAC is the cytolytic end product of the complement cascade and its accumulation on the pathogenís surface directly correlates with cell lysis. Interestingly, MAC deposition on both Patoc lig $A$ and Patoc $\operatorname{lig} B$ was significantly reduced compared to Patoc wt, further confirming a crucial role of Lig proteins on aiding pathogenic Leptospira to avoid complementmediated bacteriolysis.

Preliminary studies to assess the bacterial loads of ligtransformed $L$. biflexa strains in blood were performed and revealed that these strains presented similar half-life than wt $L$. biflexa in infected hamsters (data not shown). This data is in line with a previous study that shown that the infection with a $\operatorname{lig} B$ mutant of L. interrogans does not lead to loss of virulence and colonization in acutely and chronically infected animals, respectively [29]. Furthermore, it is worth to consider that the process of mutagenesis per $s e$ is sometimes unable to demonstrate the importance of a single virulence factor since other leptospiral proteins may provide functional redundancy $[30,37]$. By using L. biflexa as a surrogate host, we have shown that Lig proteins contribute to bacterial survival in human serum (Fig. 5), which is in line with recent results by Pappas and Picardeau [38] using Transcription Activator-Like Effectors (TALEs). These authors have shown that down regulation of both $\operatorname{lig} A$ and ligB in pathogenic $L$. interrogans is required for virulence attenuation, thus attesting the importance of the Lig proteins for a successful infection [38].

\section{Acknowledgments}

The authors do not have a commercial or other association that might pose a conflict of interest. This work was supported by the Grants2010/50043-0 and 2015/09972-0 from Fundação de Amparo à Pesquisa do Estado de São Paulo (FAPESP).

\section{References}

[1] G. Pappas, P. Papadimitriou, V. Siozopoulou, L. Christou, N. Akritidis, The globalization of leptospirosis: worldwide incidence trends, Int. J. Infect. Dis. 12 (2008) 351-357.

[2] R.B. Reis, G.S. Ribeiro, R.D. Felzemburgh, F.S. Santana, S. Mohr, A.X. Melendez, A. Queiroz, A.C. Santos, R.R. Ravines, W.S. Tassinari, M.S. Carvalho, M.G. Reis, A.I. Ko, Impact of environment and social gradient on Leptospira infection in urban slums, PLoS Negl. Trop. Dis. 2 (2008) e228.
[3] R.A. Hartskeerl, M. Collares-Pereira, W.A. Ellis, Emergence: control and re-emerging leptospirosis: dynamics of infection in the changing world, Clin. Microbiol. Infect. 17 (2011) 494-501

[4] T.R. Fraga, A.S. Barbosa, L. Isaac, Leptospirosis: aspects of innate immunity: immunopathogenesis and immune evasion from the complement system, Scand. J. Immunol. 73 (2011) 408-419.

[5] A.S. Barbosa, P.A. Abreu, S.A. Vasconcellos, Z.M. Morais, A.P. Goncales, A.S Silva, M.R. Daha, L. Isaac, Immune evasion of leptospira species by acquisition of human complement regulator C4BP, Infect. Immunol. 77 (2009) 1137-1143.

[6] T. Meri, R. Murgia, P. Stefanel, S. Meri, M. Cinco, Regulation of complement activation at the C3-level by serum resistant leptospires, Microb. Pathog. 39 (2005) 139-147

[7] T.R. Fraga, S. Courrol Ddos, M.M. Castiblanco-Valencia, I.Y. Hirata, S.A. Vasconcellos, L. Juliano, A.S. Barbosa, L. Isaac, Immune evasion by pathogenic Leptospira strains: the secretion of proteases that directly cleave complement proteins, J. Infect. Dis. 209 (2014) 876-886.

[8] K. Whaley, S. Ruddy, Modulation of the alternative complement pathways by beta $1 \mathrm{H}$ globulin, J. Exp. Med. 144 (1976) 1147-1163.

[9] J.M. Weiler, M.R. Daha, K.F. Austen, D.T. Fearon, Control of the amplification convertase of complement by the plasma protein beta1H, Proc. Natl. Acad. Sci. U. S. A. 73 (1976) 3268-3272.

[10] M.K. Pangburn, R.D. Schreiber, H.J. Muller-Eberhard, Human complement C3b inactivator: isolation characterization, and demonstration of an absolute requirement for the serum protein beta $1 \mathrm{H}$ for cleavage of $\mathrm{C} 3 \mathrm{~b}$ and $\mathrm{C} 4 \mathrm{~b}$ in solution, J. Exp. Med. 146 (1977) 257-270.

[11] M.M. Castiblanco-Valencia, T.R. Fraga, L.B. Silva, D. Monaris, P.A. Abreu, S. Strobel, M. Jozsi, L. Isaac, A.S. Barbosa, Leptospiral immunoglobulin-like proteins interact with human complement regulators factor H, FHL-1 FHR-1, and C4BP, J. Infect. Dis. 205 (2012) 995-1004.

[12] J. Scharfstein, A. Ferreira, I. Gigli, V. Nussenzweig, Human C4-binding protein. I. isolation and characterization, J. Exp. Med. 148 (1978) 207-222.

[13] I. Gigli, T. Fujita, V. Nussenzweig, Modulation of the classical pathway C3 convertase by plasma proteins C4 binding protein and C3b inactivator, Proc Natl. Acad. Sci. U. S. A. 76 (1979) 6596-6600.

[14] J. Matsunaga, M. Lo, D.M. Bulach, R.L. Zuerner, B. Adler, D.A. Haake, Response of Leptospira interrogans to physiologic osmolarity: relevance in signaling the environment-to-host transition, Infect. Immunol. 75 (2007) 2864-2874.

[15] J. Matsunaga, Y. Sanchez, X. Xu, D.A. Haake, Osmolarity: a key environmental signal controlling expression of leptospiral proteins LigA and LigB and the extracellular release of LigA, Infect. Immunol. 73 (2005) 70-78.

[16] H.A. Choy, M.M. Kelley, T.L. Chen, A.K. Moller, J. Matsunaga, D.A. Haake, Physiological osmotic induction of Leptospira interrogans adhesion: ligA and LigB bind extracellular matrix proteins and fibrinogen, Infect. Immunol. 75 (2007) 2441-2450

[17] Y.P. Lin, Y.F. Chang, A domain of the Leptospira LigB contributes to high affinity binding of fibronectin, Biochem. Biophys. Res. Commun. 362 (2007) 443-448.

[18] Y.P. Lin, Y.F. Chang, The C-terminal variable domain of LigB from Leptospira mediates binding to fibronectin. J. Vet. Sci. 9 (2008) 133-144.

[19] Y.P. Lin, A. Greenwood, L.K. Nicholson, Y. Sharma, S.P. McDonough, Y.F. Chang, Fibronectin binds to and induces conformational change in a disordered region of leptospiral immunoglobulin-like protein B, J. Biol. Chem. 284 (2009) 23547-23557.

[20] Y.P. Lin, A. Greenwood, W. Yan, L.K. Nicholson, Y. Sharma, S.P. McDonough, Y.F. Chang, A novel fibronectin type III module binding motif identified on C-terminus of Leptospira immunoglobulin-like protein, LigB. Biochem. Biophys. Res. Commun. 389 (2009) 57-62.

[21] Y.P. Lin, D.W. Lee, S.P. McDonough, L.K. Nicholson, Y. Sharma, Y.F. Chang, Repeated domains of leptospira immunoglobulin-like proteins interact with elastin and tropoelastin, J. Biol. Chem. 284 (2009) 19380-19391.

[22] Y.P. Lin, S.P. McDonough, Y. Sharma, Y.F. Chang, The terminal immunoglobulin-like repeats of LigA and LigB of Leptospira enhance their binding to gelatin binding domain of fibronectin and host cells, PLoS One 5 (2010) e11301.

[23] Y.P. Lin, R. Raman, Y. Sharma, Y.F. Chang, Calcium binds to leptospiral immunoglobulin-like protein LigB, and modulates fibronectin binding. J. Biol. Chem. 283 (2008) 25140-25149

[24] R.U. Palaniappan, Y.F. Chang, S.S. Jusuf, S. Artiushin, J.F. Timoney, S.P. McDonough, S.C. Barr, T.J. Divers, K.W. Simpson, P.L. McDonough, H.O. Mohammed, Cloning and molecular characterization of an immunogenic LigA protein of Leptospira interrogans, Infect. Immunol. 70 (2002) 5924-5930.

[25] J. Matsunaga, M.A. Barocchi, J. Croda, T.A. Young, Y. Sanchez, I. Siqueira, C.A. Bolin, M.G. Reis, L.W. Riley, D.A. Haake, A.I. Ko, Pathogenic Leptospira species express surface-exposed proteins belonging to the bacterial immunoglobulin superfamily, Mol. Microbiol. 49 (2003) 929-945.

[26] J. Croda, J.G. Ramos, J. Matsunaga, A. Queiroz, A. Homma, L.W. Riley, D.A. Haake, M.G. Reis, A.I. Ko, Leptospira immunoglobulin-like proteins as a serodiagnostic marker for acute leptospirosis, J. Clin. Microbiol. 45 (2007) 1528-1534.

[27] E. F. Silva, M.A. Medeiros, A.J. McBride, J. Matsunaga, G.S. Esteves, J.G. Ramos, C.S. Santos, J. Croda, A. Homma, O.A. Dellagostin, D.A. Haake, M.G. Reis, A.I. Ko, The terminal portion of leptospiral immunoglobulin-like protein LigA confers protective immunity against lethal infection in the hamster model of leptospirosis, Vaccine 25 (2007) 6277-6286. 
[28] S.M. Faisal, W. Yan, C.S. Chen, R.U. Palaniappan, S.P. McDonough, Y.F. Chang, Evaluation of protective immunity of Leptospira immunoglobulin like protein A (LigA) DNA vaccine against challenge in hamsters, Vaccine 26 (2008) 277-287.

[29] J. Croda, C.P. Figueira, E.A. Wunder Jr., C.S. Santos, M.G. Reis, A.I. Ko, M. Picardeau, Targeted mutagenesis in pathogenic Leptospira species: disruption of the LigB gene does not affect virulence in animal models of leptospirosis, Infect. Immunol. 76 (2008) 5826-5833.

[30] C.P. Figueira, J. Croda, H.A. Choy, D.A. Haake, M.G. Reis, A.I. Ko, M. Picardeau, Heterologous expression of pathogen-specific genes ligA and ligB in the saprophyte Leptospira biflexa confers enhanced adhesion to cultured cells and fibronectin, BMC Microbiol. 11 (2011) 129.

[31] R.C. Johnson, L.H. Muschel, Antileptospiral activity of normal serum, J. Bacteriol. 89 (1965) 1625-1626.

[32] R.C. Johnson, V.G. Harris, Antileptospiral activity of serum. II. Leptospiral virulence factor, J. Bacteriol. 93 (1967) 513-519.

[33] A. Verma, J. Hellwage, S. Artiushin, P.F. Zipfel, P. Kraiczy, J.F. Timoney, B. Stevenson, LfhA: a novel factor H-binding protein of Leptospira interrogans, Infect. Immunol. 74 (2006) 2659-2666.

[34] L.B. da Silva, S. Miragaia Ldos, L.C. Breda, C.M. Abe, M.C. Schmidt, A.M. Moro, D. Monaris, J.N. Conde, M. Jozsi, L. Isaac, P.A. Abreu, A.S. Barbosa, Pathogenic
Leptospira species acquire factor $\mathrm{H}$ and vitronectin via the surface protein LcpA, Infect. Immunol. 83 (2015) 888-897.

[35] B. Stevenson, H.A. Choy, M. Pinne, M.L. Rotondi, M.C. Miller, E. Demoll, P. Kraiczy, A.E. Cooley, T.P. Creamer, M.A. Suchard, C.A. Brissette, A. Verma, D.A. Haake, Leptospira interrogans endostatin-like outer membrane proteins bind host fibronectin, laminin and regulators of complement, PLoS One 2 (2007) e1188.

[36] A.S. Barbosa, D. Monaris, L.B. Silva, Z.M. Morais, S.A. Vasconcellos, A.M. Cianciarullo, L. Isaac, P.A. Abreu, Functional characterization of LcpA: a surface-exposed protein of Leptospira spp. that binds the human complement regulator C4BP, Infect. Immunol. 78 (2010) 3207-3216.

[37] A.J. McBride, G.M. Cerqueira, M.A. Suchard, A.N. Moreira, R.L. Zuerner, M.G. Reis, D.A. Haake, A.I. Ko, O.A. Dellagostin, Genetic diversity of the Leptospiral immunoglobulin-like (Lig) genes in pathogenic Leptospira spp, Infect. Genet. Evol. 9 (2009) 196-205.

[38] C.J. Pappas, M. Picardeau, Control of gene expression in leptospira spp by transcription activator-Like effectors demonstrates a potential role for LigA and LigB in Leptospira interrogans virulence, Appl. Environ. Microbiol. 81 (2015) 7888-7892. 